\title{
Development of the Characterizing Indicators for the Existing Biodiversity and Natural Ecosystems and Their Role in Habitat Formation
}

\author{
Alexander Myaskov ${ }^{1, *}$, Svetlana Kostyuk $^{2}$, and Dora Marinova ${ }^{3}$ \\ ${ }^{1}$ National University of Science and Technology MISiS, College of Mining, 119049, 4 Leninsky av., \\ Moscow, Russia \\ ${ }^{2}$ T.F. Gorbachev Kuzbass State Technical University, 65000028 Vesennya st., Kemerovo, Russia \\ ${ }^{3}$ Curtin University, U1987 6102 Kent Street, Bentley, Perth, Australia
}

\begin{abstract}
Particular species of living organisms contribute to our natural environment in respective particular ways. Joined together, these species form biocenoses, able to run vital natural functions. Biogeocenoses that tightly link living and non-living organisms are the basis of ecosystems, our planet and human beings as biological species in particular, as later ones are fully dependent on the environmental condition. Determining the contributions of specific species and, subsequently, ecosystems is an essential aspect of human environmental policy. Determining the importance and value of biological diversity as well as understanding of its existence is a mandatory element of environmental policy of major industrial corporations and the basis of future economic decisions of all countries.
\end{abstract}

\section{Introduction}

The complexity of biological systems and their interrelationships always have to be explained to representatives, managers of environmental policies of various industrial enterprises, many of whom ignore the loss of populations and significant ecosystem degradation.

Due to the fact that the issues of biodiversity conservation, both from the biological point of view and from the point of view of environmental management in terms of environmental measures of industrial enterprises, are currently in the spotlight, it is necessary to define precisely the concepts that need to be operated in the future by both side - biologists and representatives of industrial enterprises [1]. Biodiversity includes all living organisms (bacteria, protozoans, fungi, plants, animals) and communities of living organisms that form ecosystems (biogeocenoses). Natural ecosystems are nature-formed biogeocenoses that are the basis of life on Earth. They are characterized by the biological diversity of life forms, which is the crucial element responsible for the formation of all vital processes on the planet.

The abundance and diversity of the planet's inhabitants corresponds to the diversity of ecological niches in biogeocenoses. Millions of species are the main resource and basis of the biosphere stability. When describing the structure and properties of ecosystems, indicators of species diversity are usually the first to be indicated. In addition, structural

${ }^{*}$ Corresponding author: floranimal@,rambler.ru 
diversity, which characterizes many micro-habitats and ecological niches, and genetic diversity within populations are considered. All these indicators are important for the formation of adaptive capacity of the ecosystem.

\section{Materials and Methods}

Biological systematics divides all living organisms into taxa - groups of organisms that have common features of their morphological organization and physiological processes and at the same time are quite isolated in nature, i.e. do not have hybrids with representatives of other taxa $[2,8,12,17,21]$.

The most natural taxon is a species - classification unit of the lowest rank. The highest taxon is a Kingdom. In each of them one can find more primitive and more morphologically and physiologically complex representatives, all of them being highly adapted to their environment. The largest groups of organisms, which differ in the type of metabolic processes, food specialization and role in nature, can be distinguished as follows.

Bacteria: prokaryotes, single-celled organisms. Their genetic program, like in all living organisms, is encoded as a DNA sequence and carries information about the structure of proteins.

Due to the different energy sources used by different groups of bacteria, the roles of bacteria in nature are extremely diverse.

Many heterotrophic aerobic bacteria are the decomposers in ecosystems. In the soil, they contribute to the formation of a fertile layer, transforming forest litter and rotting animal remains into humus. Soil bacteria decompose organic compounds to minerals. It was found that huge portion of $\mathrm{CO}_{2}$ enters the atmosphere due to the activity of bacteria and fungi. Bacteria participate in biogeochemical cycles of nitrogen, sulfur, phosphorus. Selfpurification of water in natural water bodies and wastewater treatment are also performed by aerobic and anaerobic heterotrophic bacteria.

Symbiotic bacteria inhabit the intestines of herbivorous animals; bacterial microflora of the human intestine is involved in the processes of digestion of plant fiber. These bacteria also synthesize some vitamins. Nitrifying bacteria are symbionts of legumes, they enrich the soil with nitrogen.

Bacteria are used in biotechnology industries. Products of the microbiological industry are used as sources of food and fuel (biogas from plant residues). Bacteria are used in genetic engineering, for example for biotechnological production of valuable drugs. A number of bacteria are pathogens of plants, animals, and humans.

Autotrophic bacteria, both photosynthetic and chemosynthetic, are producers in some ecosystems. Currently, bacterial products are used to clean the soil from oil and other organic pollutants, to combat insect pests, etc.

Protozoans are unicellular organisms. In nature, protozoans are widespread in humid and aquatic environments. The variety of protozoans is great: near 50,000 species are described. These species are included in water and soil communities. There are also types of protozoans that are pathogens (parasite on multicellular organisms). Many protozoans are involved in wastewater treatment. Some contribute to the soil formation and, consequently, are part of soil ecosystems.

Fungi are a large and thriving group of organisms. About 100,000 species are described. A variety of fungi includes organisms such as yeast, fungi, pathogens and, finally, higher fungi, which are often large in size and consumed by animals and humans.

The role of fungi in nature is extremely large. Fungi are often symbionts (partners) of plants. Mutually beneficial relationship of fungi with the root system of plants (mycorrhiza) plays a key role in the nutrition and distribution of plants, as well as in soil formation. Symbionts of fungi with algae (lichens) inhabit unsuitable for other organisms habitats. 
In terrestrial and soil ecosystems, fungi, together with bacteria, play the role of reducing agents, feeding on dead organic matter and decomposing it. The metabolic activity of fungi is very high, as they are capable to rapidly destruct rocks and release chemical elements, which are included in the biogeochemical cycles of carbon, nitrogen and other soil and air components. Many fungi parasite on plants and animals. Some species damage wood, leather and many other organic materials, as well as food. Fungi produce biologically active substances used in medicine and biotechnology (e.g., antibiotics). From ancient times, unicellular fungi (yeast) have been used in baking, winemaking, brewing, microbiological industry.

Finally, edible mushrooms are a valuable food product and the object of special breeding.

Plants are autotrophic photosynthetic organisms, which cells contain the green pigment chlorophyll. In the Plant kingdom groups of inhabitants of water and land are distinguished. The main place in aquatic ecosystems is occupied by algae, which play the role of producers of organic matter and sources of oxygen. The smallest algae floating in the surface layers of the warm oceans. Due to rapid breeding and large total biomass, the smallest algae floating in the surface layers of the warm oceans, are important suppliers of oxygen to the entire Earth. Some algae are edible for animals and man.

In terrestrial ecosystems, the flow of energy through food chains begins with higher plants - mosses, ferns, gymnosperms and angiosperms (flower). These plants have a variety of elements for land-based lifestyles, extraction and use of water, and breeding. The most perfect group is a group of flowering (angiosperms) plants that have mastered a variety of habitats. Plants play the main role in the biosphere. The nature of the plant determines the appearance of the landscape. In ecosystems, plants, as a rule, are the dominant species that determine the nature of zoocenoses and microbiocenoses.

In farming and human life, plants also play a crucial role as a source of food, building material, medicinal and other biologically active substances. Plant communities of the paleobiosphere have created the reserves of fossil fuels currently used by man. The vegetation cover of the planet regulates climate, hydrological regime, serves as the basis for the ability of ecosystems to self-purification. Plants make extensive use of modern biotechnology to produce food biomass, drugs, and biomass for energy purposes.

Animal Kingdom includes heterotrophic organisms, most of which are capable of active movement and nutrition. In ecosystems animals represent trophic levels of consuls (herbivores, small and large predators, necrophages). The variety of animals is very large. In the Animal Kingdom, biological systematics distinguishes different types of body structure, which are associated with the peculiarities of the basic life functions. Animal Kingdom can be divided into two large groups - invertebrates and vertebrates.

Animal species diversity plays an important role in the regulation of biocenoses and the existence of nature. Many species of animals are bred and fished by humans. Domestic and agricultural animals have been companions of mankind on the way of civilization.

The contribution of living organisms to the existence of nature and the list of their use by humans are presented in Table 1.

Combined together, populations of different species in ecosystems create sustainable biogeochemical cycles, which maintain the constancy of modern living environments - soil, land and water. Ecosystems are capable of self-regulation and restoration of balance of populations of many species interacting with each other in biocenoses. Trophic relationships between species are of particular importance for ecosystem homeostasis. In nature, the number of species representing the main ecological groups of organisms is naturally combined: producers (plants), consulates (animals) and decomposers (bacteria and fungi). The more diverse each group is represented, the more sustainable the ecosystem as a whole is due to the interchangeability of species. In biogeocenoses, the diversity of biological species supports stable cycles of biogens, chemical elements that make up living organisms 
(oxygen, carbon, hydrogen, nitrogen, phosphorus, calcium, sulfur, etc.), through which solar energy is absorbed and transformed in the biosphere, resources are obtained and waste is processed $[3,4,7,10,11,14,19,21]$.

Table 1. The contributions of living organisms to the existence of humans and nature.

\begin{tabular}{|c|c|c|}
\hline & Contribution to nature & Use by humans \\
\hline $\begin{array}{l}\text { Bacteria and } \\
\text { protozoans }\end{array}$ & $\begin{array}{l}\text { Decomposition } \\
\text { Formation of fertile layer } \\
\text { Formation of mineral substances } \\
\text { Regulation of atmospheric composition } \\
\text { Participation in biogeochemical cycles } \\
\text { Water self-cleaning } \\
\text { Synthesis of vitamins }\end{array}$ & $\begin{array}{l}\text { Food biotechnology } \\
\text { Fuel biotechnology } \\
\text { Drugs biotechnology } \\
\text { Removing dirt } \\
\text { Pest control }\end{array}$ \\
\hline Fungi & $\begin{array}{l}\text { Decomposition } \\
\text { Formation of fertile layer } \\
\text { Formation of mineral substances } \\
\text { Participation in biogeochemical cycles }\end{array}$ & $\begin{array}{l}\text { Food biotechnology } \\
\text { Drug biotechnology } \\
\text { Food resource }\end{array}$ \\
\hline Plants & $\begin{array}{l}\text { Production } \\
\text { Regulation of atmospheric composition } \\
\text { Regulation of biocenoses } \\
\text { Regulation of landscape } \\
\text { Self-cleaning of ecosystems }\end{array}$ & $\begin{array}{l}\text { Food resources } \\
\text { Building resources } \\
\text { Fuel resources } \\
\text { Social resources } \\
\text { Drugs } \\
\text { Minerals } \\
\text { Food biotechnology } \\
\text { Fuel biotechnology } \\
\text { Drug biotechnology }\end{array}$ \\
\hline Animals & $\begin{array}{l}\text { Consumption } \\
\text { Regulation of biocenoses }\end{array}$ & $\begin{array}{l}\text { Food resources } \\
\text { Hunt resources } \\
\text { Social resources }\end{array}$ \\
\hline
\end{tabular}

The diversity of biological species is vital for the stability of synthesis cycles, as well as transformation and destruction of organic matter of the biosphere. In natural ecosystems, biota maintains balance between production and destruction of organic matter with high accuracy. In addition, biota provides effective management of hydrological regime, composition of soil, atmosphere, water. Some sources claim that biota retains this ability to the full if humanity uses no more than $1 \%$ of the net primary production of biota. The rest of the products should be used to support the life of species that stabilize the environment.

As a result of human activity and the functioning of industrial facilities, biogeochemical cycles are disrupted: phytocenoses are disrupted and their productivity decreases; the share of heterotrophic units in ecosystems increases; part of the biomass of plants is withdrawn from the cycle in favor of man. In addition, a huge amount of waste, which decomposition by natural reducing agents is impossible, is accumulated.

In science, all animal or plant species are traditionally evaluated as unique biological and systematic units, that are formed in the process of long-term evolution and have, therefore, specific sets of adaptations to the appropriate environmental conditions of the environment. These sets of adaptations, defined and characterized by the biological parameters of each particular species, provides the potential continuity of the species in time and space. When qualitative and/or quantitative changes in environmental or other conditions under the influence of limiting factors exceed the possibilities of adaptive properties of the species, the species degrades and finally disappears. The duration and intensity of the degradation process can be different. The main essence of the degradation process is the steady prevalence of mortality over the annual population growth. Without active human intervention, the 
direction and the results of such a process are always unambiguous. The group of species, which has entered the process of degradation, is called rare or endangered species. Such species are marked in red lists, including the Red book of the Russian Federation, which gives these species a special ecological and legislative status $[1,5,6,9,13,16,20]$.

\section{Results and Discussion}

The process of degradation of species, followed by extinction, can follow different scenarios, depending on the ecological specificity of the species, determined by the biological indicators (parameters) of each particular species. These biological indicators include:

1. Population. Population and its change over time is the most important integrated indicator of vulnerability of a species and its status as a whole. At the same time, positive or negative changes in the population are normal, and it is necessary to clearly distinguish natural (seasonal, annual, long-term) fluctuations in the population from a steady and continuous decline. Such negative type of population dynamics first of all indicates the process of degradation, deep change of all or the majority of ecological conditions necessary for the species on all area.

2. Area structure. It is a space on Earth that has been historically or artificially inhabited by a particular species during all or some seasons of the year for a sufficiently long period of time. When analyzing an area as a biological parameter, it is necessary to take into account a certain variability of its configuration and space boundaries associated either with natural causes or with the impact of anthropogenic factors (industrial or other construction, plowing, deforestation, artificial change of the hydro network and other anthropogenic processes). The anthropogenic impact usually leads to irreversible changes in areal structure, mostly unfavorable for the existence of the species. One of the most important consequences of the anthropogenic impact is fragmentation, disintegration of the area into a number of more or less isolated habitats of the species. Deep fragmentation has an extremely negative impact on all levels: population decline, changes in population structure, increased mortality, emergence of negative genetic processes.

3. Ecological specifics of a species. Each species is adapted to a specific range of environmental factors that determine its relationship with the environment. For some species, the required set of these adaptations is quite wide and flexible. Such species can successfully exist under different conditions regardless of the biological qualities of the natural environment. These species are much more successful in adapting to the anthropogenic changes in the area and often find optimal conditions for maintaining high numbers. In contrast, other groups of species are closely and rigidly related to a narrow range of environmental factors. The disturbance or deficiency of such factors, usually directly or indirectly related to anthropogenic transformation of the area, leads to the inevitable degradation of these sensitive and highly specialized species. Therefore, when it is needed to identify possible causes of the species vulnerability and eliminate them, it is important to characterize and evaluate the ecological specifics of the species.

4. Breeding success and mortality. The ratio of fertility, breeding success and mortality is an important biological parameter that determines the annual growth of the population, and the very dynamics of the population over long periods of time, and trends in its changes. The variability of this biological parameter can have both natural (weather conditions, feed supply, etc.) and anthropogenic (habitat disturbance, chemical pollution effects, disturbance of population structure, etc.) reasons.

5. Population structure. Like most other biological parameters, the structure of the population (horological, sexual, age, social) regularly or periodically undergoes certain transformations, the causes and depth of which can be both natural (seasonal, long-term or other) and anthropogenic. This should be taken into account in the analysis and evaluation of these 
changes. In particular, shifts in the sex and age structure of the population may result from selective overexploitation of the population and at the same time cause a decrease in the potential for breeding. Special attention should be paid to the indicators characterizing the effective population size, that is, the number and percentage of mature individuals in the population. A steady decline in these indicators is an alarm sign.

6. Relationship with the area. Reaction of a species to the changes happening in the area, as long as many other biological parameters, varies relatively widely. For some species, the change or complete destruction of typical natural (original) areas under the influence of anthropogenic or other factors causes loss of forage, loss of sites and conditions for successful breeding, aggravation of interspecies relations, changes in other vital environmental factors. The consequence of this is, first and foremost, the downsizing and fragmentation and/or reduction of the area, standing, as a rule, for the beginning of the degradation process. For other species, loss of typical areas does not entail such catastrophic consequences, and in some cases, creates additional opportunities for expansion of the area. It should be emphasized that the loss of typical areas is not always the main limiting factor. This should be taken into account when developing projects to restore extinct or create new populations of species on the verge of extinction.

7. Migration. The need for migration and the ability to do so are more or less characteristic of the vast majority of animals. For long-term seasonal migrants (birds) this means that there is a regular and unavoidable need to spend considerable time both on the migration route and on wintering sites, where the basic natural conditions and various anthropogenic impacts are fundamentally different from those found in the original nesting sites. Therefore, as a rule, almost the entire period between two successive breeding seasons is characterized by a special vulnerability of birds and is accompanied by their increased mortality, which must be compensated. For migrating mammals, this aspect is smoothed to a certain extent, but not completely eliminated. This creates a special specificity and additional complexity in the protection of all migratory animals, giving it a distinct international character.

8. Attitude towards humans. The reaction to humans appearing in areas that are of particular importance for the existence of the species (places of feeding, breeding, molting, concentration on migration routes, etc.), of different species and even different individuals of the same species varies and forms a wide range from ignoring to leaving the area of visual contact. Small mammals and birds, as well as all other systematic groups of animals, react mostly neutral, and the humans do not cause negative emotions or stress. The number of typical anthropophobia (species that not tolerates the presence of humans) is relatively small and much lower than the number of species-anthropophilous, which make up the group of sinanthropic. Among anthropophobic mammals, in most cases, are large predators and many species of ungulates; among birds those are cranes, pelicans, bustards, eagles, storks, and several other species of large size.

Using the abovementioned systematization and indicators that describe the characteristics of living organisms, it is necessary to return to the considered systematization of ecosystems and identify indicators that describe them as a set of elements of biodiversity.

Species diversity. This indicator shows the number of different species living in the ecosystem. It is believed that the more species inhabit the ecosystem, the more stable it is. This is due to the fact that one species can theoretically simply replace another in the food chain and in the ecosystem; more different species transform and produce more natural energy, more minerals, etc.; linked together, different ecosystems work better, creating a complex of ecosystems, passing one to another, etc.

Structural diversity. The more diverse the ecosystem is, the more sustainable it is. For example, in an ecosystem that includes both elevation changes and extensive water bodies, and noticeable seasonal variability, and therefore species, the processes of global ecosystem change may occur much faster and less noticeably. 
Degree of uncertainty indicates the level of change and degradation of the ecosystem, which in turn indicates the speed of response to negative impacts and reactions of living organisms, and as a consequence, the integrity of the entire system.

Uniqueness is probably one of the most important indicators in terms of responding to negative impact. The more unique the ecosystem is, the more complex and dependent the internal connections within such a system are. With the uniqueness of the system and the species that inhabit it, they are much more difficult to reproduce, restore and reintroduce. Also, the more unique an ecosystem is, the more valuable it is to humanity, including both current and future generations.

Ecosystem area, its size is an important indicator, partly describing the complexity of the ecosystem of the environment, primarily anthropogenic load and, on the other hand, showing the real size of the natural community resisting such a load.

The importance of the ecosystem for the planet is defined by the presence of elements that perform global environmental functions, restoring various balances on the planet. Regulation of atmospheric composition, climate, water composition, conservation of migration and reproduction are the contribution of ecosystems to the existence of the planet. The more similar the functions performed by the ecosystem are, the higher its significance is.

Ability to regenerate after being subjected to a negative impact is a very important indicator of an ecosystem when considering the extent of disturbance and the priority of the choice of conservation measures for such an ecosystem.

Level of human consumption. Partly, this is an economic indicator showing how many resources can be extracted from a given ecosystem. If we are talking about deforestation in a certain region, or industrial fishing, the level of such consumption is very high. If a National park with recreational area and ecological routes is established to conserve an ecosystem, the level of consumption is low.

Table 2. The existing indicators of biodiversity and ecosystems.

\begin{tabular}{|l|ll|}
\hline \multirow{4}{*}{ Level } & \multicolumn{1}{|c|}{ Indicator } \\
\hline \multirow{4}{*}{ Ecosystems } & 1. & Species diversity \\
\cline { 2 - 3 } & 2. & Structural diversity \\
\cline { 2 - 3 } & 3. & Level of disturbance \\
\cline { 2 - 3 } & 4. & Uniqueness \\
\cline { 2 - 3 } & 5. & Area \\
\cline { 2 - 3 } & 6. & Global environmental functions \\
\cline { 2 - 3 } & 7. & Ability to regenerate \\
\hline \multirow{4}{*}{ Living organisms } & 8. & Level of human consumption \\
\cline { 2 - 3 } & 9. & Population \\
\cline { 2 - 3 } & 10. & Area structure \\
\cline { 2 - 3 } & 11. & Ecological specifics \\
\cline { 2 - 3 } & 12. & Breeding success \\
\cline { 2 - 3 } & 13. & Population structure \\
\cline { 2 - 3 } & 14. & Relationship with the area \\
\cline { 2 - 3 } & 15. & Migrations \\
\cline { 2 - 3 } & 16. & Attitude towards humans \\
\hline \multirow{4}{*}{} & &
\end{tabular}

\section{Conclusion}

Thus, the process of degradation of species and natural ecosystems, followed by extinction and excessive irreplaceable violations, can follow different scenarios, depending on the 
ecological specificity of the species and ecosystem, determined by biological and environmental indicators (parameters) of each specific object. These indicators were systematized with their reference to natural ecosystems and living organisms. A general list of biodiversity indicators is presented in Table 2. Having identified specific indicators of existing biodiversity, it is necessary to determine the factors influencing industrial e enterprises on the environment in a particular region or on a global scale, the patterns of influence of these factors, which, in turn, will allow to identify the consequences of such impact and suggest measures to minimize it. [20].

\section{References}

1. M. Coll, L.J. Shannon, K.M. Kleisner, Ecological Indicators, 60, 947-962 (2016)

2. W. Rabitsch, P. Genovesi, R. Scalera, M. Josefsson, F. Essl, Journal for Nature Conservation, 29, 89-96 (2016)

3. R. Belley, P.V.R. Snelgrove, Frontiers in Marine Science, 3, 242 (2016)

4. L. Contoli, L. Luiselli, Web Ecology, 15:1, 33-37 (2015)

5. T. Gao, A.B. Nielsen, M. Hedblom, Ecological Indicators, 57, 420-434 (2015)

6. A. Böhnke-Henrichs, C. Baulcomb, R. Koss, S.S. Hussain, R.S. de Groot, Journal of Environmental Management, 130, 135-145 (2013)

7. O.P. Melekhova, Complex systems, 1:6, 27-49 (2013)

8. Z.-Q. Zhang, Zootaxa, 3703, 1-82 (2013)

9. G. Capotorti, D. Guida, V. Siervo, D. Smiraglia, C. Blasi, Biological Conservation 147:1, 174-183 (2012)

10. A.V. Myaskov, Mining information and analytical bulletin (scientific and technical journal), 1, 399-401 (2011)

11. A., Li, B.L. Chakraborty, Journal of Arid Land, 3:1, 71-74 (2011)

12. M.A. McGeoch, S.H.M. Butchart, D. Spear, J, Chanson, M. Hoffmann, Diversity and Distributions 16:1, 95-108 (2010)

13. A.V., Myaskov, E.Yu. Biryulina, Mining information and analytical bulletin (scientific and technical journal), 7, 237-240 (2010)

14. A.V. Myaskov, Mining information and analytical bulletin, 6:12, 260-265 (2009)

15. N. Salafsky, D. Salzer, A.J. Stattersfield, S. O'Connor, D. Wilkie, Conservation Biology, 22:4, 897-911 (2008)

16. J.V. Higgins, M.T. Bryer, M.L. Khoury, T.W. Fitzhugh, Conservation Biology, 19:2, $432-445 \quad(2005)$

17. V. Carignan, M.-A. Villard, Environmental Monitoring and Assessment, 78:1, 45-61 (2002)

18. National biodiversity conservation strategy for Russia (Russian Academy of Sciences, Moscow, 2001)

19. F. Schläpfer, B. Schmid, Ecological Applications 9:3, 893-912 (1999)

20. Jr.J. Cairns, P.V. McCormick, B.R. Niederlehner, Hydrobiologia, 263:1, 1-44 (1993)

21. J.R. Newman, R.K. Schreiber, Environmental Management, 8:4, 309-324 (1984)

22. A.V. Myaskov, A.S. Tulupov, O.V. Zhironkina, V.S., Zaitsev, Russian Journal of Industrial Economics, 11:3, 273-279 (2018) DOI: https://doi.org/10.17073/2072-16332018-3-273-279 